\title{
THERMAL CONDUCTIVITY AND IMPACT PROPERTIES OF IRON ORE TAILINGS FILLED EPOXY COMPOSITES
}

\author{
M. A. Onitiri ${ }^{1}{ }^{*}$, S. A. Oladosu ${ }^{2}$ and Y. B. Adebayo ${ }^{3}$ \\ 1, DePARTMENT OF MECHANICAL ENGINEERING, UNIVERSity of LAGOS, AKOKA, LAGOS STATE, NIGERIA.

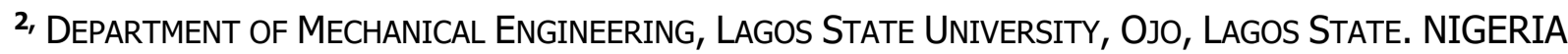 \\ 3. Dept. of Engineering TeChnology, Black HaWk College, 4703 16th St G, Moline, IL 61265, USA. \\ Email addresses: ${ }^{1}$ monitiri@unilag.edu.ng, ${ }^{2}$ dolarestnajem@gmail.com, ${ }^{3}$ badmos@bhc.edu
}

\begin{abstract}
Iron ore tailings which is the waste material derived from the beneficiation of iron ore was dispersed in epoxy as micro scale particle fillers. The effect of particle size and particle loading on the thermal conductivity and impact properties of the composites were then investigated experimentally. A comparison of the experimental results for the former to results obtained from existing theoretical models was also done. It was discovered that the impact resistance increased with increasing volume content of iron ore tailings from $20 \mathrm{vol}$ \% with a maximum toughness of $0.098 \mathrm{kJm}^{-2}$ recorded for composite with $300 \mu \mathrm{m}$ at $30 \mathrm{vol}$. \%. Thermal conductivity of epoxy improved with decreasing particle size while the Maxwell, Lewis and Nelson and parallel models gave reasonable predictions for epoxy filled with $212 \mu \mathrm{m}$ at $10 \mathrm{vol} \%$ and $20 \mathrm{vol}$. \% contents; with least variations of $0.18 \%$ and $1.26 \%$, respectively.
\end{abstract}

Keywords: Composite, Epoxy, Impact, Iron ore tailings, Particle size, Particle loading, Thermal conductivity

\section{INTRODUCTION}

Most modern design requires material with unusual combination of properties that cannot be met by conventional metals, metal alloys, ceramics and polymeric materials. The rapid increase in global population has led to corresponding increase in the consumption and exploration of this conventional materials with its negative environmental implications $[1,2]$. Composite materials have, over the years, been adopted to address the above issues [3-7]. In the case of polymer, inorganic particles such as micro-/nano$\mathrm{SiO}_{2}, \mathrm{Al}_{2} \mathrm{O}_{3}, \mathrm{CaCO}_{3}$, glass and carbon nanotubes are often added to improve their limitations (namely; low rigidity, low stiffness, low hardness, poor thermal and poor electrical conductivity) and to expand its application in different areas [3,7-9].Properties of the polymer matrix composites with particle inclusions are influenced by the particle size, the particle loading, the particle/matrix interfacial adhesion and the manufacturing processes $[9,10]$.This work intends to determine, experimentally, the effect of particle size and particle loading on the impact properties and thermal conductivity of epoxy filled with iron ore tailings while the experimental thermal conductivity results will be compared with results obtained from existing theoretical models.

The use of metallic and nonmetallic particles as fillers in polymers relates chiefly to applications requiring a certain degree of rigidity, hardness, toughness, abrasion, electrical conductivity, magnetic permeability, sound absorption and thermal conductivity. Nonmetallic particle filled polymer composites find applications as structural materials in construction, packaging, automobile tyres, medicine, etc. while metal particle filled polymer composites are used in applications such as discharging static electricity, heat conduction (e.g heat spreaders in notebook computers), electrical heating and communications. Previous works shows that stiffness and strength of particulate-filled polymer composites can be improved by addition of either micro- or nanoparticle $[9,11-13]$. This is possible due to the higher

* Corresponding author, tel: +234-802-889-8844 
stiffness property of the fillers compared to the polymer matrices while strength is improved by enhanced bonding between the particles and the matrices culminating to easy stress transfer between the particle and the matrices [9, 14-17]. It has also been discovered that for applications which require high thermal conductivity, polymers which has lower thermal conductivity than those for metals or ceramic metals, exhibit improved thermal conductivity when organic or inorganic materials are added as fillers [1821]. Adedayo and Onitiri's [22] work on the impact behaviour of iron ore tailings filled-polypropylene composites shows that Izod impact strength decreases with particle size but increases with increasing volume content of iron ore tailings from $5 \%$ to $25 \%$ for each particle size considered. In another work by Teh et al. [23] on the effect of particulate fused silica, glass powder and mineral silica on the thermal and the dynamic mechanical properties of epoxy composites, it was found that dynamic thermal mechanical properties and coefficient of thermal expansion (CTE) increase and reduce, respectively, with increasing volume of fillers. The highest toughness value was observed at filler content 40 vol\%. In a related work, Zhang et al. [24] conducted thermal conductivity, impact and tensile tests on $\mathrm{Al}_{2} \mathrm{O}_{3} /$ high density polyethylene (HDPE) composites and found that thermal conductivity and tensile strength of the composites increased with decrease in particle size. Highest impact strength was exhibited by HDPE filled with $0.5 \mu \mathrm{m}$ particle size $\mathrm{Al}_{2} \mathrm{O}_{3}$ at 25 vol\% content while nano-size particulate fillers lead to reduction in impact strength due to agglomeration of the particles caused by their high surface energy.

\section{THEORY}

The thermal properties of a two-phase composite system, comprising of a continuous matrix and particulate filler, is a function of the properties of the constituent phases, their relative amounts and the geometry of the dispersed particle [25]. Several theoretical and empirical models have been proposed to predict the effective thermal conductivity of such

$$
\left.\begin{array}{rl}
k_{c} & =k_{m} \frac{1+A \cdot \beta \cdot \phi}{1-\beta . \phi . \psi} \\
\text { where } \beta & =\frac{k_{f} / k_{m}-1}{k_{f} / k_{m}+A} \quad \text { and } \quad \psi=1+\frac{1-\phi_{m}}{\phi_{m}{ }^{2}} \phi
\end{array}\right\}
$$

composites. Some of the existing models are hereby presented.

The two basic models representing the upper and lower bound for thermal conductivity of composites are the rule of mixture also known as the parallel model and the series model $[21,25]$. The former assumes perfect contact between particles and that each phase is assumed to contribute independently to the overall conductivity while the latter assumes no contact between particles and thus the contribution of particles is confined to the region of matrix embedding the particle. The parallel model is shown as equation (1):

$$
k_{c}=\phi k_{f}+(1-\phi) k_{m}
$$

while for the series model is equation (2):

$$
\frac{1}{k_{c}}=\frac{\phi}{k_{f}}+\frac{1-\phi}{k_{f}}
$$

where, $\phi$ is the volume fraction of filler and, $k_{m}, k_{f}$ and $k_{c}$ are thermal conductivities of matrix, filler and composite, respectively.

Lewis and Nielsen [25-27] derived a semi-theoretical model to account for the effect of the shape of the particles and the orientation or type of packing for a two-phase system by modifying the Halpin-Tsai equation as shown in equation (3) below.

The constant $A$ depends upon the shape and orientation of the dispersed particles. $\phi_{m}$ is the maximum packing fraction of the dispersed particles. $A=1.5$ and $\phi_{m}=0.637$ for randomly packed spherical particles whereas for randomly packed aggregates of spheres or for randomly packed, irregularly shaped particles $A=3$ and $\phi_{m}=0.637$.

Cheng and Vachon's $[25,28]$ modification of Tsao's probabilistic model assumed a parabolic distribution of the discontinuous phase. The constants of the parabolic distribution were evaluated as a function of the discontinuous phase volume fraction while the effective thermal conductivity is given for the case $k_{f}>k_{m}$ as equation (4): 


$$
\begin{aligned}
& \frac{1}{k_{c}}=\frac{1}{\left.\sqrt{C\left(k_{f}-k_{m}\right)\left(k_{m}+B\left(k_{f}-k_{m}\right)\right.}\right)} \ln \frac{\left.\sqrt{k_{m}+B\left(k_{f}-k_{m}\right)}+B / 2 \sqrt{C\left(k_{f}-k_{m}\right.}\right)}{\left.\sqrt{k_{m}+B\left(k_{f}-k_{m}\right)}-B / 2 \sqrt{C\left(k_{f}-k_{m}\right.}\right)}+\frac{1-B}{k_{m}} \\
& \text { where } \quad B=\sqrt{\frac{3 \phi}{2}} \quad \text { and } \quad C=-4 \sqrt{\frac{2}{3 \phi}}
\end{aligned}
$$

Maxwell [29] and other researchers [21, 25] obtained a simple relationship for the conductivity of randomly distributed and non-interacting homogeneous spheres in a homogeneous medium using potential theory. This is shown in equation (5) below;

$$
k_{c}=k_{m} \frac{k_{f}+2 k_{m}+2 \phi\left(k_{f}-k_{m}\right)}{k_{f}+2 k_{m}-\phi\left(k_{f}-k_{m}\right)}
$$

\section{MATERIAL AND EXPERIMENTATION}

The epoxy resin is produced by Adefolorunsho Technical enterprises, Nigeria, under the brand name 'virgin epoxy'®. The epoxy resin was formed by reacting epichlorohydrin with bisphenol $A$. The particulate filler for this investigation is iron ore tailings from iron ore beneficiation plant in Itakpe, Kogi State in the North central region of Nigeria. It is approximately irregular in shape.

\subsection{Iron ore tailings preparation}

The iron ore tailings was dried at room temperature $30 \pm 2^{\circ} \mathrm{C}$ for a minimum of 40 hours prior to testing [30 - 32] while the different particle sizes were generated using standard ASTM laboratory sieves $[33$, 34]. The uppermost of the ASTM sieve arrangement was loaded with iron ore tailings and vibrated for about 6 minutes. After vibrating, the sieve arrangement was dismantled and the tailings deposited in each sieve were weighed and recorded. The volume mix ratios adopted in this work are 0 to $30 \%$ at intervals of $5 \%$ while the particle sizes are 150, 212 and $300 \mu \mathrm{m}$.

\subsection{Production of iron ore tailings filled epoxy composite test specimens}

The dimensions of the impact and thermal conductivity test specimens are in conformity with ASTM D 256 and ASTM D 5930 specimen specifications, respectively $[35,36]$.The method used by Adedayo and Onitiri [37] was adopted for the production of the iron ore tailings filled epoxy composites. One and three parts of epichlohydrin (hardener) and epoxy, respectively, were poured into a clean plastic container and stirred thoroughly with a wooden rod. Appropriate quantity of iron ore tailings was then added and stirred thoroughly so as to obtain a perfect mix and remove air. The poly (vinyl chloride) (PVC) film was fixed between the wooden base and the cavity strip. Then the mix was then poured and another PVC film was placed on the filled cavity followed by the wooden top. The arrangement was then clamped using the two threaded bolt and locking nut. The cast was allowed to cure for 80 minutes before the rig was dismantled and the cast removed. This procedure was carried out for different particle sizes and corresponding volume content of iron ore tailings. Five specimens were produced for each mix ratio.

\subsection{Impact and thermal conductivity test}

The Izod impact and thermal conductivity tests were conducted on the composites produced under standard laboratory atmosphere [23, 24]. The test specimens were conditioned at room temperature $30^{\circ} \mathrm{C} \pm 2^{\circ} \mathrm{C}$ for a minimum of 40 hours prior to testing [30 - 32]. Conditioning was carried out to obtain reproducible results [30]. The Izod impact test was conducted as specified in ASTM D 256 using an Avery impact testing machine of capacity $4.2 \mathrm{~J}$ and striking velocity $2.44 \mathrm{~m} / \mathrm{s}$. The specimen was positioned perpendicular to the jaw of the vice and clamped firmly but not too tightly, with the end to be impacted projecting above the vice. The pendulum was released and the excess energy in the pendulum after impact was recorded. The needle probe technique was used for thermal conductivity test on the iron ore tailings [38] and the composites [36] using the KD2 Pro meter kit produced by Decagon Devices Inc. The needle probe technique, also referred to as the linesource method, is a variant of the hot wire method $[39,40]$. The TR 1 sensor was adopted for the thermal conductivity test. The needle probe was positioned at the center of the test specimen with both kept at constant initial temperature. A heat wave which propagates radially in the specimen is generated by producing a known amount of heat in 
the needle. The linear relationship between the temperature rise in the probe and the logarithm of time was used to obtain the thermal conductivity of the test specimen which is shown on a digital display unit.

\section{RESULTS AND DISCUSSION}

Figure 1 shows the Izod impact toughness of iron ore tailings filled epoxy composites against 150, 212 and $300 \mu \mathrm{m}$ particle size volume fraction content of 0-30 $\%$ vol. iron ore tailings at intervals of $5 \% \mathrm{vol}$. particle inclusion.

It can be seen that, though addition of iron ore tailings reduces the impact toughness of epoxy resin, the impact property of the composite improved with increased particle inclusion from 1.83 and 1.62 $\mathrm{kJ} / \mathrm{m}^{2}$ (at $15 \mathrm{vol} . \%$ ) to 2.32 and $2.25 \mathrm{~kJ} / \mathrm{m}^{2}$ (at 30 vol.\%) for 150 and $212 \mu \mathrm{m}$, respectively. $300 \mu \mathrm{m}$ exhibited the highest impact strength from 15 vol.\% to $30 \mathrm{vol} . \%$ with a value of $2.74 \mathrm{~kJ} / \mathrm{m}^{2}$. It is significant to note that the 20 and 30 vol.\% point, for low particle size inclusion, where epoxy composites exhibited approximately equal Izod impact toughness at variations of 0.05 and $0.07 \mathrm{~kJ} / \mathrm{m}^{2}$, respectively. Liu et al. [41] also noted the significance of the 20 and 30 vol.\% in their work on the effect of $\mathrm{CaCO}_{3}\left(\mathrm{~d}_{\mathrm{p}}=\right.$ $0.6 \mu \mathrm{m}$ ) volume fraction on the izod impact toughness of $\mathrm{CaCO}_{3}$ filled high density polypropylene composites with various weight ratio of coupling agent. The Izod impact toughness for the composites peaked at 20 vol. $\%$ while poor toughening was shown at $30 \mathrm{vol}$.\%. The Izod impact toughness is also found to increase with decreasing particle size in the particle volume fraction range studied. This is similar to findings reported by Bartczak et al. [42] and Zhang et al. [43] for $\mathrm{CaCO}_{3}$ filled polymer composite under Izod impact loading. The former worked with polyethylene while the later used polypropylene matrices. Figure 2 shows the thermal conductivity versus volume of 150,212 and $300 \mu \mathrm{m}$ iron ore tailings in epoxy.

It is observed that the thermal conductivity of epoxy improved with reducing particle size; with the highest value of $0.35 \mathrm{~W} / \mathrm{m}-\mathrm{K}$ recorded for $30 \mathrm{vol}$. \% inclusion of $150 \mu \mathrm{m}$ particle size fillers. It can also be seen that the thermal conductivity increases with increasing particle inclusion except for particle size $300 \mu \mathrm{m}$ where the reverse is the case. The increase in thermal conductivity for the smaller particle sizes could be attributed to the improved particle compaction culminating into better surface area contact. One the other hand, reduction in thermal conductivity for 300 $\mu \mathrm{m}$ is due to the large particle size which leads to reduced surface area of particle contacting each other.

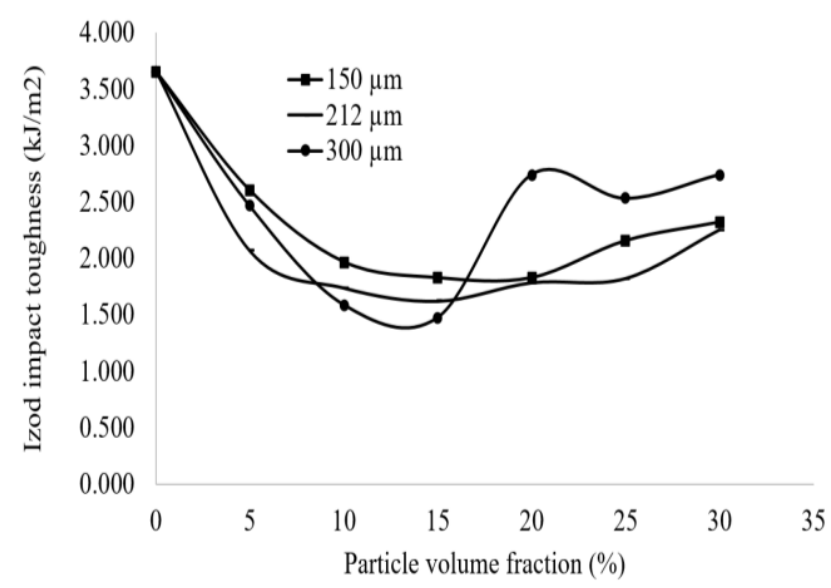

Figure 1: Notch Izod impact toughness of iron ore tailings filled epoxy composites versus iron ore tailings particle content

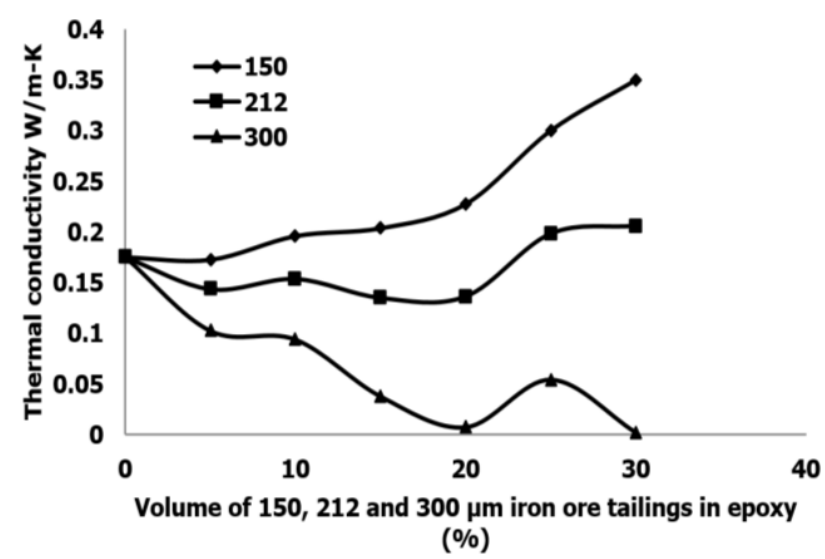

Figure 2: Thermal conductivity versus volume of 150, 212 and $300 \mu \mathrm{m}$ iron ore tailings in epoxy

Figure 3, 4 and 5 shows the thermal conductivity versus volume of iron ore tailings in epoxy for particle sizes 150, 212 and $300 \mu \mathrm{m}$. In these figures, the experimental results are compared with the Cheng and Vachon, [25, 28] Maxwell, [21, 25, 29] Lewis and Nelson, [25-27] parallel, [21, 25] and series,[21,25] models. It can be seen that the experimental values reduces with increasing particle size when compared to the Maxwell, Lewis and Nelson and the parallel models. The three models gave reasonable predictions of the thermal conductivity of the composites with particle inclusion $212 \mu \mathrm{m}$ for $20 \%$ and below. The best predictions occurred at $10 \%$ and $20 \%$ volume of $212 \mu$ mparticle with least variations of $0.18 \%$ and $1.26 \%$, respectively. The Cheng and 
Vachon model predicted the trend of the thermal conductivity of the composite with $300 \mu \mathrm{m}$ inclusion with the best prediction occurring at $20 \%$ and $30 \%$ volume content of iron ore tailings.

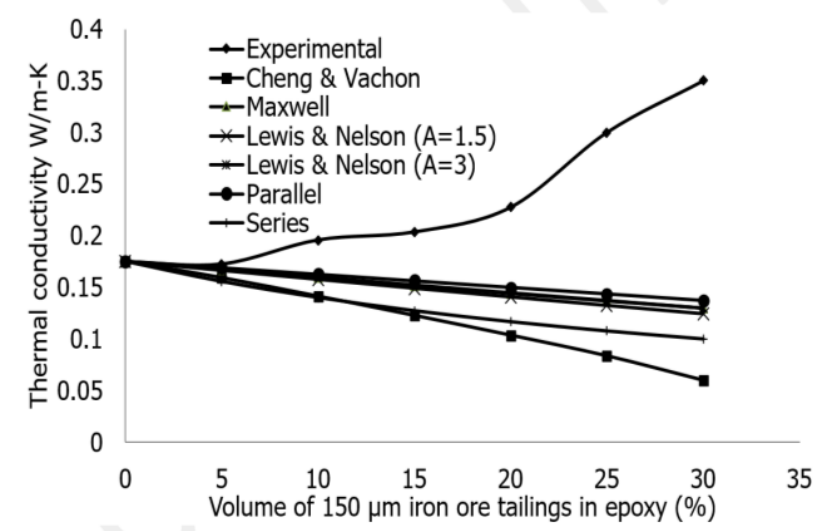

Figure 3: Thermal conductivity versus volume of 150 $\mu m$ iron ore tailings in epoxy

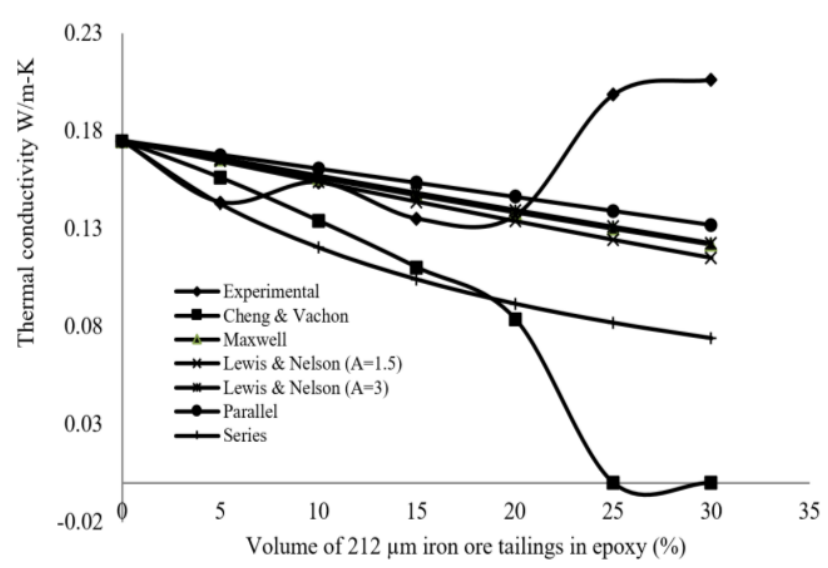

Figure 4: Thermal conductivity versus volume of 212 $\mu m$ iron ore tailings in epoxy

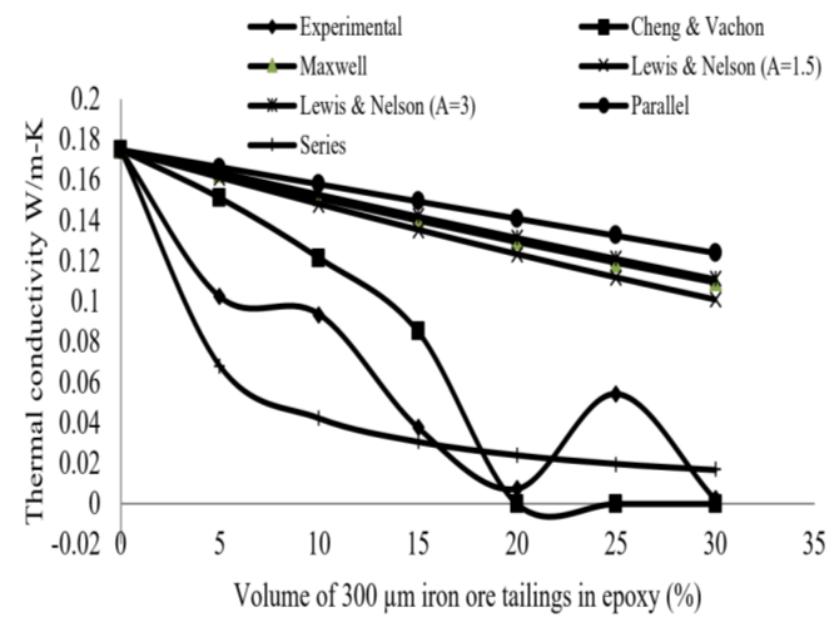

Figure 5: Thermal conductivity versus volume of 300 $\mu m$ iron ore tailings in epoxy

\section{CONCLUSION}

Impact strength of the composites with small particle sizes increased from 20 to $30 \mathrm{vol} \%$ after the initial drop at lower \% volume. Composites with $300 \mu \mathrm{m}$ inclusions exhibited the greatest impact resistance at volumes greater than $16.5 \%$. The thermal conductivity of epoxy improved with reduced particle size and increasing volume content for 150 and 212 $\mu \mathrm{m}$ particle fillers. The Maxwell, Lewis and Nelson and the parallel models a reasonable prediction of epoxy composites with $212 \mu \mathrm{m}$ particle size fillers at volumes below $21 \%$.

\section{REFERENCES}

[1] Onitiri, M. A. Effects of Temperature on the Mechanical Properties of Extruded Virgin and Recycles Unplasticized Polyvinyl Chloride (UPVC) Plastics, [dissertation], University of Ilorin, 2002.

[2] Onitiri, M. A. and Adeniyi, J. S. O. "Effects of temperature on the tensile properties of extruded virgin and recycled unplasticized polyvinylchloride (UPVC) plastics", Nigerian Journal of Technological Development, Vol. 3, Number 2, 2003, pp 80-87.

[3] Maiti, S. N. and Mahapatro, P. K. "Mechanical properties of i-PP/CaCO3", Journal of Applied Polymer Science, Vol. 42, Number 12, 2011, pp 3077-3273.

[4] Rahman, R., Hasan, M., Huque, M. and Islam N. "Physico-mechanical properties of maleic acid post treated jute fiber reinforced polypropylene composites", Journal of Thermoplastic Composites Materials, Vol. 22, Number 4, 2009, pp 365-381.

[5] Rahman, R., Huque, M., Islam, N. and Hasan M. "Mechanical properties of polypropylene composites reinforced with chemically treated abaca", Composites Part A, Vol. 40, Number 4, 2009, pp 511-517.

[6] Reddy, G. V., Naidu, S. V. and Rani, T. S. "A Study on Hardness and Flexural Properties of Kapok/Sisal Composites", Journal of Reinforced Plastics and Composites, Vol. 28, Number 16, 2009, pp 2035-2044.

[7] Chandrakala, K., Vanaja, A. and Rao, R. "Storage Life Studies on RT Cure Glass-Epoxy Pre-pregs", Journal of Reinforced Plastics and Composites, Vol. 28, Number 16, 2009, pp 1987-1997.

[8] Wang, J. High-Temperature Deformation of $\mathrm{Al}_{2} \mathrm{O}_{3} / \mathrm{Y}$-TZP Particle Composites and Particulate 
Laminates, [dissertation], The University of Texas at Austin, 2003.

[9] Fu, S., Feng, X., Lauke, B. and Mai, Y. "Effects of particle size, particle/matrix interface adhesion and particle loading on mechanical properties of particulate-polymer composites", Composites Part B: Engineering, Vol. 39, Number 6, 2008, pp 933-961.

[10] Onitiri, M. A. and Adedayo, S. M. "Compressive behaviour of polypropylene filled with iron ore tailings", Journal of Engineering, Design and Technology, Vol. 13, Number 2, 2015, pp 198212.

[11] Zhu, Z. K., Yang, Y., Yin, J. and Qi, Z. "Preparation and properties of organosoluble polyimide/silica hybrid materials by sol-gel process", Journal of Applied Polymer Science, Vol. 73, Number 14, 1999, pp 2977-2984.

[12] Radford, K. C. "The mechanical properties of an epoxy resin with a second phase dispersion", Journal of Material Science, Vol. 6, Number 10, 1971, pp 1286-91.

[13] Amdouni, N., Sautereau, H. and Gerard, J. F. "Epoxy composites based on glass-beats. 2. Mechanical-properties", Journal of Applied Polymer Science, Vol. 46, Number 10, 1992, pp 1723-35.

[14] Hsueh, C. H. "Effects of aspect ratios of ellipsoidal inclusions on elastic stress transfer of ceramic composites", Journal of American Ceramics Society, Vol. 72, Number 2, 1987, pp 344-7.

[15] Pukánszky, B, and Voros, G. "Mechanism of interfacial interactions in particulate filled composites", Composite Interface, Vol. 1, Number 5, 1993, pp 411-427.

[16] Young, R. J. and Beaumont, P. W. R. "Failure of brittle polymers by slow rack growth - Part 3: Effect of composition upon the fracture of silica particle-filled epoxy-resin composites", Journal of Material Science, Vol. 12, Number 4, 1978, pp 643-657.

[17] Nakamura, Y., Yamaguchi, M., Okubo, M.and Matsumoto, T. "Effects of particle size on mechanical and impact properties of epoxy resin filled with spherical silica", Journal of Applied Polymer Science, Vol. 45, Number 7, 1992, pp 1281-1289.
[18] Kumlutas, D., Tavman, I. H. and Coban, M. T. "Thermal conductivity of particle filled polyethylene composite materials", Composites Science and Technology, Vol. 63, Number 1, 2003, pp 113- 117.

[19] Ishida, H., inventor; Edison Polymer Innovation Corporation, assignee. Composition for forming high thermal conductivity polybenzoxazinebased material and method, United States patent US 5,900,447. 1999 May 4.

[20] Ishida, H., inventor; Edison Polymer Innovation Corporation, assignee. Surface treated boron nitride for forming a low viscosity high thermal conductivity polymer based on boron nitride composition and method, United States patent US Patent, 6,160,042. 2000 Dec 12.

[21] Ebadi-Dehaghani, H. and Nazempour, M. "Thermal conductivity of nanoparticles filled polymers", In: Hashim A, editor. Smart nanoparticles technology. Rijeka: In Tech, 2012, pp.519-540.

[22] Adedayo, S. M. and Onitiri, M. A. "Mechanical properties of iron ore tailings filledpolypropylene composites", Journal of Mineral\& Material Characteristics\& Engineering, Vol. 11, Number 7, 2012, pp 671-678.

[23] The, P. L, Jaafar, M., Akil, H. M. and Beh, K. S. "Thermal and mechanical properties of particulate fillers filled epoxy composites for electronic packaging application", Polymer for Advanced Technologies, Vol. 19, Number 4, 2008, pp 308-315.

[24] Zhang, S., Cao, X. Y., Ma, Y. M., Ke, Y. C., Zhang, J. K. and Wang, F. S. "The effects of particle size and content on the thermal conductivity and mechanical properties of Al2O3/high density polyethylene (HDPE) composites", Express Polymer Letters, Vol. 5, Number 7, 2011, pp 581-590.

[25] Tavman, I. H. "Thermal and mechanical properties of aluminum powder-filled highdensity polyethylene composites", Journal of Applied Polymer Science, Vol. 62, Number 12, 1996, pp 2161-2167.

[26] Lewis, T. B. and Nielsen, L. E. "Dynamic mechanical properties of particulate-filled polymers", Journal of Applied Polymer Science, Vol. 14, Number 6, 1970, pp 1449-1471. 
[27] Nielsen, L. E. and Landel, R. F. Mechanical Properties of Polymers and Composites, Marcel Dekker Inc, New York, 1994.

[28] Cheng, S. C. and Vachon, R. I. "The prediction of the thermal conductivity of two and three phase solid heterogeneous mixtures", International Journal of Heat Mass Transfer, Vol. 12, Number 3, 1969, pp 249-264.

[29] Maxwell, J. C. A Treatise on Electricity and Magnetism, Dover, New York, 1954.

[30] ASTM D618, Standard Practice for Conditioning Plastics for Testing, ASTM International, 2013.

[31] ASTM E171 / E171M-11, Standard Practice for Conditioning and Testing Flexible Barrier Packaging, ASTM International; 2015.

[32] ASTM E41-92, Terminology Relating to Conditioning, ASTM International; 2010.

[33] Adepoju, S. O. and Olaleye, B. M. "Gravity concentration of silica sand from Itakpe iron-ore tailings by tabling operation", Nigerian Journal of Engineering Management, Vol. 2, 2001, pp 51-55.

[34] Olubambi, P. A. and Potgieter, J. H. "Effectiveness of gravity concentration for the beneficiation of Itakpe (Nigeria) iron ore achieved through jigging operation", Journal of Minerals\& Materials Characteristics\& Engineering, Vol. 4, Number 1, 2005, pp 21-30.

[35] ASTM D256-10e1, Standard Test Methods for Determining the Izod Pendulum Impact Resistance of Plastics, ASTM International; 2010.

[36] ASTM D5930, Standard Test Method for Thermal Conductivity of Plastics by Means of a
Transient Line-Source Technique, ASTM International; 2009.

[37] Adedayo, S. M. and Onitiri, M. A. "Tensile properties of iron ore tailings filled epoxy composites", The West Indian Journal of Engineering, Vol. 35, Number 1, 2012, pp 5159.

[38]ASTM D5334, Standard Test Method for Determination of Thermal Conductivity of Soil and Soft Rock by Thermal Needle Probe Procedure, ASTM International; 2008.

[39] Sekhu, K. S. and Singh, P. "Various methods for measuring thermal conductivity-A review", Journal of Mechanical and Civil Engineering, Vol. 2, Issue 5, Paper 17, 2015, pp 87-92.

[40] ISO 22007-1, Plastics - Determination of thermal conductivity and thermal diffusivity Part 1: General Principles, International Standard, 2009.

[41] Liu, Z. H., Kwok, K. W., Li, R. K. Y. and Choy, C. L. "Effects of coupling agent and morphology on the impact strength of high density polyethylene/CaCO3 composites", Polymer, Vol. 43, Number 8, 2002, pp 2501-2506.

[42] Bartczak, Z., Argon, A. S., Cohen, R. E. and Weinberg, M. "Toughness mechanism in semicrystalline polymer blends: II. High-density polyethylene toughened with calcium carbonate filler particles", Polymer, Vol. 40, Number 9, 1999, pp 2347-2365.

[43] Zhang, L., Li, C. and Huang, R. "Toughness mechanism in polypropylene composites: PP toughened with elastomer and calcium carbonate", Journal of Polymer Science Part B: Polymer Physics, Vol. 42, Number 9, 2004, pp 1656-1662. 